\title{
Experimental Equipment for Investigation of Soybean Storage with Active Ventilation
}

\author{
Sholpan Duisenova ${ }^{1 *}$, Aibek Atykhanov', Dimitar Karaivanov², \\ Bekbossyn Kassymbayev ${ }^{1}$, Kabdyrakhim Kalym', Aigul Sagyndikova ${ }^{3}$ \\ 1 Kazakh National Agrarian University, Abay Avenue, 8, Almaty, 050010, Kazakhstan \\ 2 University of Chemical Technology and Metallurgy, Kliment Ohridski Blvd., 8, 1756 Sofia, Bulgaria \\ 3 Almaty University of Power Engineering and Telecommunications, Almaty, 050013, Kazakhstan \\ * Corresponding author's e-mial: sholp.kz@mail.ru
}

\begin{abstract}
The article investigates and substantiates the operating modes of container-modular equipment with active ventilation, such as specified (real) productivity, power consumption of the conveying process, as well as the use of a progressive method of controlling the humidity and temperature in soybean storage volume. The experimental equipment which adequately simulates the proposed technology for soybean storage with active ventilation for the calculated data verification was developed. The experiments confirmed that the proposed experimental equipment enables to adequately simulate the process of soybean storage with active ventilation and conduct experiments with the regulation of basic parameters such as productivity, power consumption, humidity, etc. using modern methods, devices and digital technologies. The experimental results were presented. Humidity and temperature were monitored during the experiments using the "Strazh Klimat" software. The experimental data were obtained, enabling to establish the dependence of the conveying height on the air flow velocity.
\end{abstract}

Keywords: active ventilation, air flow velocity, conveying height, flow rate, power consumption, productivity.

\section{INTRODUCTION}

Currently, in agriculture, the increase and preservation of the soybean crop remains one of the main problems, since the soy products are the main source of environmentally friendly protein balanced in amino acid composition (Silva et al., 2009). Due to the high content of protein and fat, as well as the increased hygroscopicity of seeds, soybeans quickly deteriorate under adverse conditions (the presence of organic impurities, high moisture level, etc.). Even dry seeds warm themselves in the presence of impurities (Jangurazov \& Jangurazov, 2013). Nowadays, soybeans are the leading culture of world agriculture, the pinnacle of excellence and universality throughout the plant world. Soybean is central to solving the protein problem and quite profitable. The soybean seeds contain $38-42 \%$ protein, $18-23$ fat, $25-30 \%$ carbohydrates, as well as enzymes, vitamins, and minerals. Due to its rich and diverse chemical composition, soy is unparalleled in terms of the production growth rates; it has long been used as a universal food, feed and oilseed crop (Singh, 2010). It has no analogues in plant resources in terms of productivity and quality composition. As already noted, the main condition for the safe storage of soybean is to reduce the moisture content in it to a certain level, which depends on the duration of storage and the ambient temperature. It is that easy to prevent the harmful effects of micro-organisms and fungi, as well as to reduce the gas exchange of grain (Chi et al., 2011). However, these should not be neglected when laying soybeans for long-term storage (more than three to four weeks) (Yukish \& Ilina, 2009). Since the grain has a very low thermal conductivity, the thermal energy is released in the center of the hopper and comes to the surface very slowly. When the grain is stored in large tower silos, heat 
will gradually accumulate until the temperature in the center of the silos reaches a sufficient level for heat exchange with the environment through the walls, until the temperature equalizes. In particular, under hot climatic conditions, this temperature equalization can never be established, since the temperature of soybean grains will continue to increase under the influence of a self-sustaining mechanism, and will exceed the level of ambient temperature by several degrees (Navarro, 2006).

Under such conditions, it is necessary not only to dry the grain to reduce the gas exchange (up to 13-14\%), but also to cool it to the lowest possible temperature immediately before laying it in storage. Thus, if it is possible to reach a temperature below the ambient temperature, due to the thermal insulation properties of the grain, this will slow down the heat penetration into the grain from the environment (Kamanula et al., 2010). Therefore, for reliable storage, it is necessary to maintain a sufficiently low air temperature between the grain space in order to inhibit the development of fungi and prevent self-heating (Parimala et al., 2013; MAK, 2015).

The main reason for the decline in the soybean quality during storage is the fungal grout (Fleurat-Lessard, 2017). Thus, during the storage of soybean with a moisture content of 11-12.5\% during the year, the minimum growth of fungi is observed only at the end of its storage. Fungi are also absent for 270 days of storage at a seed moisture content of $14-14.5 \%$ and a storage temperature of $5^{\circ} \mathrm{C}$. At a temperature of $4.5^{\circ} \mathrm{C}$, they grow very poorly or do not grow at all. Moreover, they do not develop at air humidity of $65 \%$ and lower as well as within the limits of seed moisture from 11 to $12 \%$ (Lamond \& Graham, 1993).

Moreover, humidity is more important than for other crops. It is also important to consider it for soybean and in order to maintain germination, soybean should be stored at a moisture content $1 \%$ lower than that for the soybean stored for sale and processing.

In the cold northern region of Kazakhstan, the maximum moisture content for soybean for longterm storage should be $11-11.5 \%$, while in the southern region $-10-10.5 \%$. The safe moisture levels of storing soybean depend on air temperature, material quantity, and also on the intended purpose of the grain: for processing, for fodder or for seeds.

During the storage of soybean in large quantities for a long time in warm weather, it is necessary to provide ventilation to prevent the development of mold and self-heating, even when the moisture content is low (Bokusheva et al., 2012). Without ventilation, the grain may turn rancid and discolour, which will reduce its quality. For better ventilation, the grain should be clean from plant debris, and the number of damaged, cracked seeds should be minimal (Kazanina, 1988).

The effect of grain moisture on storage is complicated by the fact that the moisture in the hopper moves. In the cool period, cold air at the walls drops, and warm air rises in the center of the hopper, taking the moisture from the grain with this stream. During this process, moisture increases in the central upper part of the hopper. Thus, in the hoppers with average grain moisture of $12-13 \%$ in the upper part, it rises to $16-17 \%$, which can reduce the soybean quality.

The basic requirements for high-quality soybean storage are as follows: the moisture content should be $10-10.5 \%$, relative air humidity below $60 \%$, temperature from -5 to $+5{ }^{\circ} \mathrm{C}$ (Chang et al., 1993). The soybean seed storage premises must be cleaned, disinfected and well-ventilated. Soybean seeds are stored in steel hoppers, in closed storage premises, in bags at stacks of $1.5-2.5 \mathrm{~m}$ high, and marketable in steel hoppers, in bulk or in hoppers with active ventilation.

Active ventilation is used not only for cooling or protecting the wet grain from self-heating, but also for drying (Aniskin, 1972). For active ventilation of grain for the purpose of drying, the atmospheric or heated air is used. The drying speed depends on the air humidity, the air temperature, the moisture-release ability of the grain, the specific air supply, and the permissible drying time. For drying grains by ventilation in summer and early autumn, warm atmospheric air with a relative humidity of up to $65-75 \%$ is used. Such drying is slow and requires a large amount of air (Sakun, 1974). Under the conditions of Belarus, it takes more than three days to remove $1 \%$ moisture with an air supply of $100 \mathrm{~m}^{3}$. In order not to spoil the grains, it is impossible to dry them for more than 6-10 days, and therefore the specific air supply during drying should be much higher than when cooling (Vasilev, 1986). The progressive and cost-effective way of soybean storage in container-modular equipment with active ventilation proposed by the authors eliminates many of these drawbacks.

The idea that standard containers (for goods transporting) with a capacity of $10-40 \mathrm{~m}^{3}$ should 
be used as containers for grain (soybeans) storage has been developed earlier (Atyhanov et al., 2018, Atykhanov et al., 2018, 2019). Each module consists of a selected container, a pneumatic conveying aggregate, pipelines, and monitoring and control instruments. The proposed equipment (Fig. 1) contains a hopper for grain storage, characterized in that the hopper is a vertically located container, while its lower part (bottom) is conical at an angle of at least $40^{\circ}$ and the lower hole is connected through a nozzle to the pneumatic conveyor and on the inner side, at three equidistant levels along the height of the container, humidity sensors are placed. A sensor control and a monitoring panel is installed on the outside of the container (Atyhanov et al., 2018).

The equipment for grain storage with active ventilation performs three cycles: loading, venting and unloading and operates as follows (Atykhanov et al., 2018; Duisenova et al., 2019):

- Loading of grain (Figure 1) into an equipped container 2 from a vehicle 3 is carried out by a pneumatic conveying aggregate 1 through a loading pipeline 9 , then through a vertical pipeline 7 into a cyclone 5, where the air-grain flow is separated into air, which is removed through a nozzle 15 , and into grain, which is settled down in container 2 for storage. The gate valve in the lower part of the cyclone 5 is driven by an electric motor.

- Active ventilation of grain in container 2 is carried out in a closed loop with the pneumatic conveying aggregate 1 from the lower nozzle 12 of the container through a two-way valve 14 , then through the vertical pipeline 7 , the cyclone 5 , and returns to the storage container 2 .

- Unloading of grain from the storage container is made through its lower nozzle by the pneumatic conveying aggregate 1 , through the twoway valve 14, a pipeline 8 through a cyclone 6 into a vehicle 3 .

This technology demands research and further substantiation of the main operating modes of the container-modular equipment with active ventilation, such as its actual productivity, the power consumption for the process of grain conveying and ventilation in an enclosed space, as well as the use of an advanced method of soybean moisture and temperature control.

The aim of this study was to develop experimental equipment that adequately simulates the proposed technology for storage of soybean with active ventilation, for subsequent verification of the calculated data.

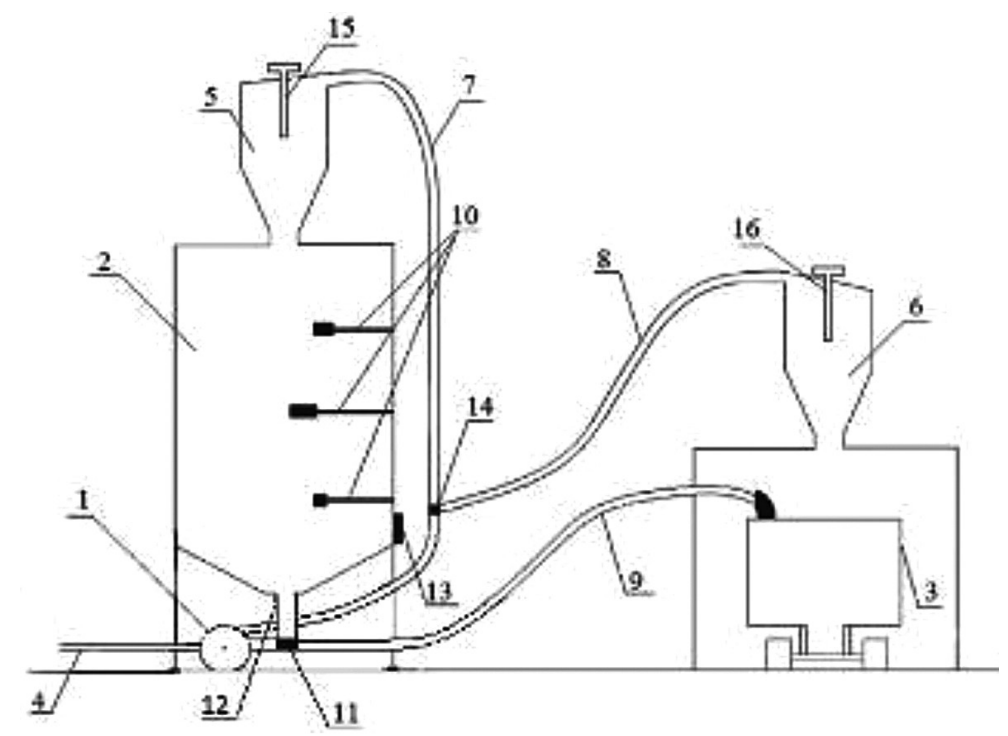

Fig. 1. Equipment for grain storage with active ventilation (Atykhanov et al., 2018)

1 - pneumatic conveying aggregate; 2 - container (hopper); 3 - vehicle from onto which the grain is loaded and from which it is unloaded; 4 - power transmission; 5 and 6 - grain separating (discharging) cyclones-unloaders; 7 - pipeline for active ventilating or loading; 8 - pipeline for unloading; 9 - pipeline (hose) for loading of grain mass; 10 - moisture sensors; 11 - two-way valve; 12 - lower nozzle; 13 - sensor control and monitoring panel; 14 - two-way valve; 15 and 16 - nozzles (with filters) for removal of air flow from the cyclones 


\section{MATERIALS AND METHODS}

\section{Experimental equipment}

Experimental equipment (Fig. 2) was developed for the purpose of the research. The equipment simulates the proposed technology according to Fig. 1 and works in three modes - loading (Fig. 3), ventilation (Fig. 4), and unloading (Fig. 6).

In Figure 1, a vacuum cleaner is shown as sucking equipment but a blower (STIHL ${ }^{\circledR} \mathrm{BGE}$ 71, see Fig. 12) can be used, too. In both cases, the air flow velocity can be changed continuously by an inverter (variable-frequency drive).

The possibilities of this experimental equipment are:

- Air flow velocity change and measurement;

- Power consumption measurement;

- Soybean moisture and temperature measurement;

- Conveying height change.

On the basis of these measurements, several input data for theoretical calculations can be determined:

- Air flow rate and material (soybean) flow rate;

- Relation between the air flow velocity and conveying height;
- Relation between the drying time and conveying parameters;

\section{TEST PROCEDURES}

\section{Flow rate and power consumption determination}

For the flow rate and the power consumption determination, $1 \mathrm{~kg}$ soybean has been loaded from the drum into the container. The height of vertical conveying is $1.5 \mathrm{~m}$. The loading time and power consumption were measured and ten tests were made. The soybean loading is carried out from the drum 8 , through the pipeline 4 , through the cyclone 2 (which separates the grain), and into the container 1 for grain storage (Fig. 3).

\section{Grain moisture determination}

The experimental equipment allows for the investigation of the drying process during the active ventilation of the material. The ventilation of grain in the container 1 was carried out in a closed loop from the bottom of the container, through the nozzle 11, through the pipeline 4, through the cyclone 2, and into the container 1 (Fig. 4).



Fig. 2. Experimental equipment for grain (soybean) storage with active ventilation: 1 - container; 2 and 3 - cyclones-unloaders; 4 - pipeline for active ventilating or loading; 5 - pipeline for unloading; 6 - PC monitor; 7 - sucking equipment (blower or vacuum cleaner); 8 - drum for grain loading from it and unloading into it; 9 - power consumption measuring instrument; 10 - temperature and humidity sensor; 11 - lower nozzle. (Phot. S. Duisenova) 


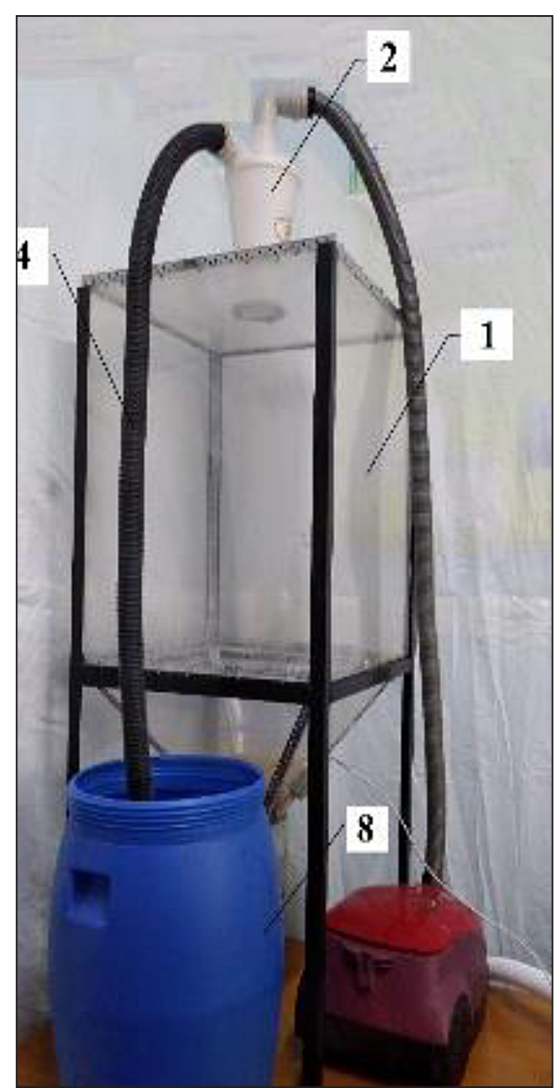

Fig. 3. Soybean loading into the container (Phot. S. Duisenova)

It is appropriate to use $1 \mathrm{~kg}$ soybean with various moisture content and ventilation time.

\section{Air flow velocity determination}

The air flow measurements were carried out with a MASTECH ${ }^{\circledR}$ MS6252A handheld digital anemometer. This anemometer is a windmill type digital measuring instrument and is used to measure wind speed and air flow (Fig. 5).

\section{Other possibilities of the experimental equipment}

The unloading process can be simulated, too (Fig. 6). Unloading of grain from the container 1 occured from the nozzle 11, through the pipeline 5 , through the cyclone 3 , and into the drum 8 , from where the grain is loaded and unloaded. In its present form, the experimental equipment allows for an increase in the conveying height to a maximum of $2.0 \mathrm{~m}$. However, when it is built in a more suitable premise, experiments can be carried out while changing the conveying height in wider boundaries (Loveykin \& Kostin, 2012).

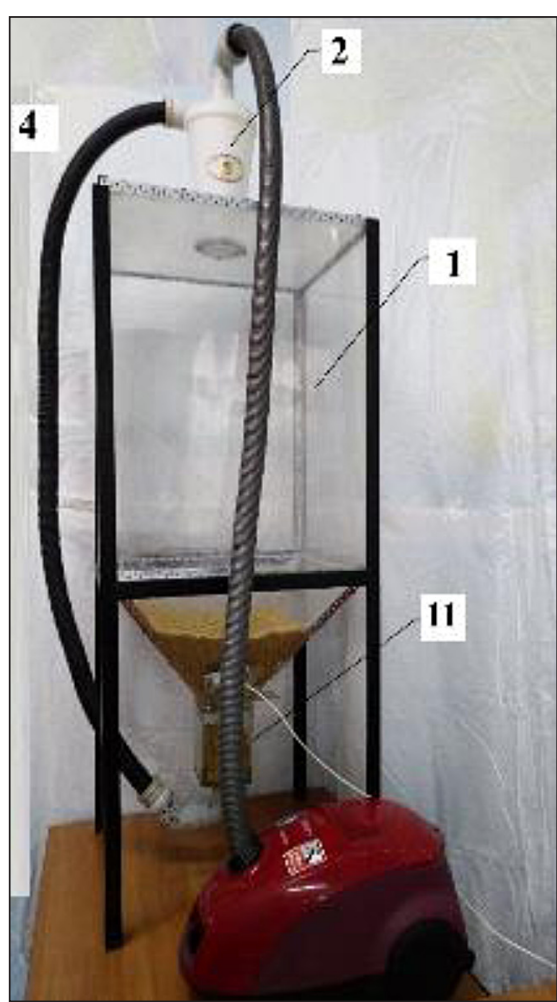

Fig. 4. Soybean active ventilation (Phot. S. Duisenova)

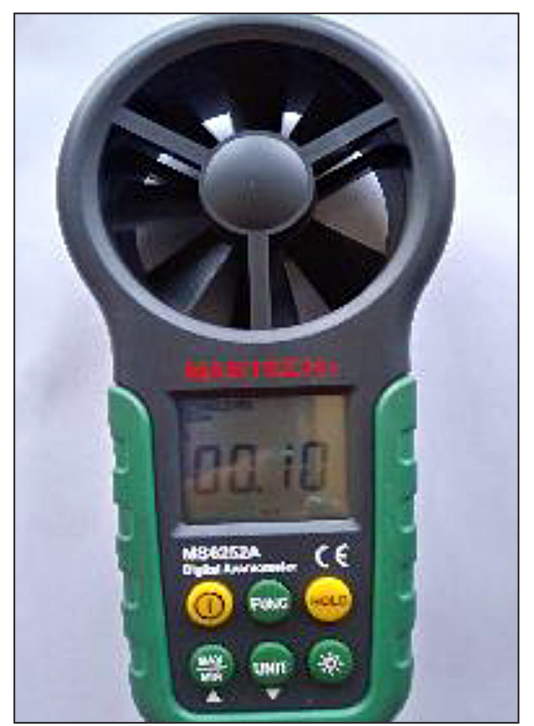

Fig. 5. MASTECH ${ }^{\circledR}$ MS6252A handheld digital anemometer, wind speed meter, and air flow tester

(Phot. S. Duisenova)

\section{TEST RESULTS}

\section{Flow rate determination}

The experimental data of the loading times for $1 \mathrm{~kg}$ soybean at conveying height of $1.5 \mathrm{~m}$ are presented in Table 1. 


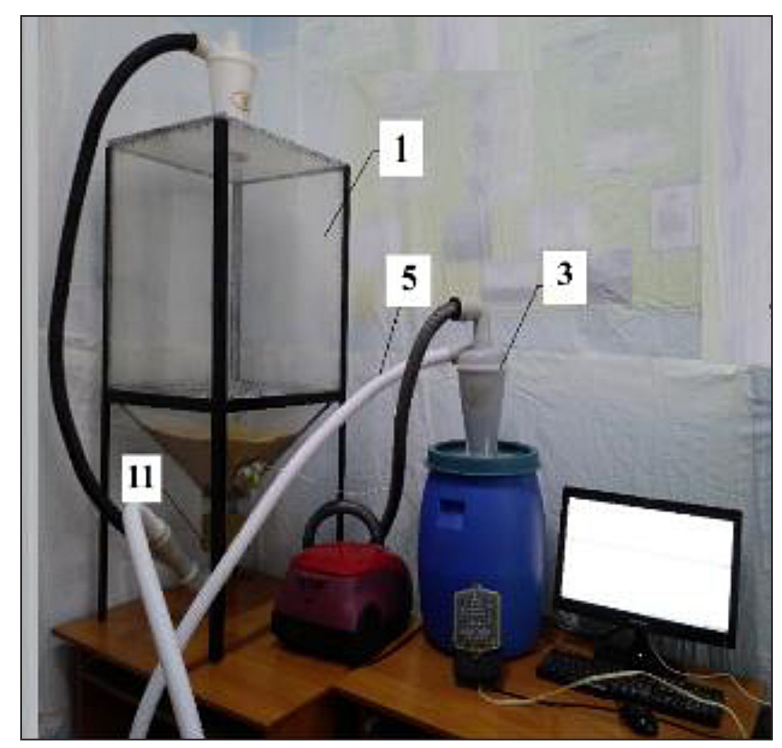

Fig. 6. Soybean loading from the container into the drum

(Phot. S. Duisenova)

From the obtained data, the mass flow rate of the equipment can be calculated by the following formula (Turaev et al., 2015):

$$
Q=\frac{m \cdot 3600}{\tau_{0}}
$$

where $Q$ - mass flow rate, $\mathrm{kg} / \mathrm{h}$;

$m$ - grain mass, $\mathrm{kg}$;

$\tau_{0}$ - loading time, $\mathrm{s}$;

The mass flow rates for each test (calculated by formula (1)) and the average one are presented in Table 1.

\section{Power consumption determination}

The power consumption is measured during the loading process. The experimental data of the loading times and power consumption for $1 \mathrm{~kg}$ soybean at conveying height of $1.5 \mathrm{~m}$ are presented in Table 2, $\tau_{0}$ and power consumption $P$ determined for $1 \mathrm{~kg}$ soybean conveyed at $1.5 \mathrm{~m}$ height (Fig. 3).

The power consumption during the active ventilation will be the same because both loading and ventilation are processed at the same height of $1.5 \mathrm{~m}$.

\section{Grain moisture and temperature determination}

The grain moisture before and after ventilation is determined as follows:
The initial moisture content of soybean was determined using Framcomp ${ }^{\circledR}$ Wile 65 meter. Then ventilation was carried out for 3 hours. The residual moisture of the material was determined with the same device.

At the same time, a SOFTRON ${ }^{\circledR}$ SM-200 temperature and humidity sensor (Fig. 8) is connected to the container. The measurement range and error of the sensor are as follows:

- Temperature: $-40-+60{ }^{\circ} \mathrm{C} \pm 0.5^{\circ} \mathrm{C}$,

- Humidity: $0-100 \%, \pm 4.5 \%$.

The sensor is connected to the computer via an adapter and is regulated using the software of "Strazh-Klimat" system (Alarm-Climate.HT1) which provides continuous control, display of the current values, and maintains archive of temperature and humidity during ventilation and storage (Monitoring system Alarm-Climate). The software sets the maximum and minimum values of temperature and humidity. Figures 9, 10, and 11 show the test results during three-hour ventilation.

\section{Air flow velocity determination}

The main component of the process productivity is the air flow velocity which should be 1.5-2 times higher than the soybean terminal velocity (Martyanova, 2017).

The soybean terminal velocity was determined through a separate experiment (Asoiro \& Chidebeluq, 2014) in the laboratory "Agricultural Engineering and Technology" of the Kazakhstan Research Institute of Agriculture Mechanization and Electrification, Almaty, Kazakhstan (Fig. 12). The test showed an average value of $v_{0}=13 \mathrm{~m} / \mathrm{s}$.

Table 1. Experimental data of the loading times $\tau_{0}$ and mass flow rates $Q$ determined for $1 \mathrm{~kg}$ soybean conveyed at $1.5 \mathrm{~m}$ height (Fig. 3)

\begin{tabular}{|c|c|c|}
\hline Test number & Loading time $T_{0}, \mathrm{~S}$ & Mass flow rate $Q, \mathrm{~kg} / \mathrm{h}$ \\
\hline 1 & 55 & 65.4 \\
\hline 2 & 53 & 66.9 \\
\hline 3 & 57 & 64.8 \\
\hline 4 & 55 & 65.8 \\
\hline 5 & 50 & 67.3 \\
\hline 6 & 60 & 66.1 \\
\hline 7 & 55 & 66.05 \\
\hline 8 & 53 & 66.1 \\
\hline 9 & 57 & 66.1 \\
\hline 10 & 55 & 65.95 \\
\hline Average & 55 & $\mathbf{6 6 . 0 5}$ \\
\hline
\end{tabular}


Table 2. Experimental data of loading times

\begin{tabular}{|c|c|c|}
\hline Test number & Working time $I_{0}, \mathbf{s}$ & $\begin{array}{c}\text { Power consumption } P, \\
\text { Wh }\end{array}$ \\
\hline 1 & 55 & 19 \\
\hline 2 & 53 & 17 \\
\hline 3 & 57 & 18 \\
\hline 4 & 55 & 18 \\
\hline 5 & 50 & 19 \\
\hline 6 & 60 & 17 \\
\hline 7 & 55 & 17 \\
\hline 8 & 53 & 19 \\
\hline 9 & 57 & 18 \\
\hline 10 & 55 & 18 \\
\hline Average & $\mathbf{5 5}$ & $\mathbf{1 8}$ \\
\hline
\end{tabular}

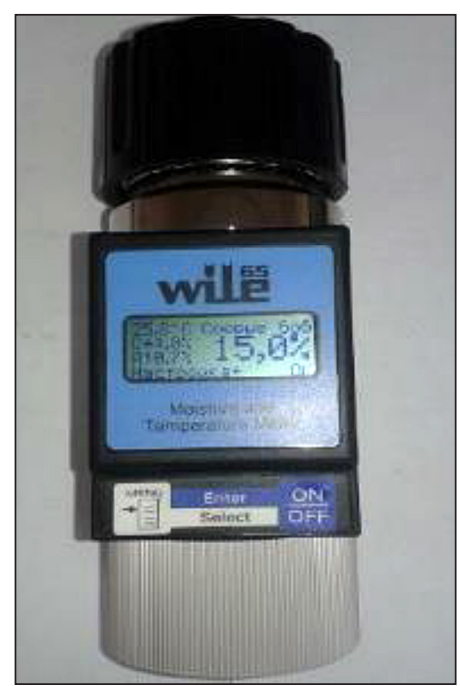

Fig. 7. Framcomp ${ }^{\circledR}$ Wile 65 grain moisture meter (Phot. S. Duisenova)

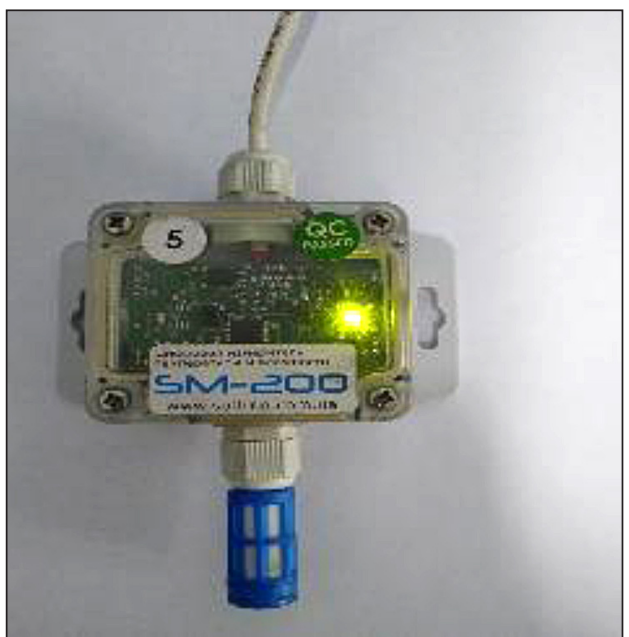

Fig. 8. Temperature and humidity sensor SOFTRON ${ }^{\circledR}$ SM-200

(Phot. S. Duisenova)
It was determined on the developed experimental equipment (Fig. 3) that an air speed of $v=20 \mathrm{~m} / \mathrm{s}$ is required for conveying the grain mass to a height of $H=1.5 \mathrm{~m}$. At the height of $H=2.0 \mathrm{~m}$, the required air speed is $v=20.1 \mathrm{~m} / \mathrm{s}$. These values can be used as a starting point for calculating the required air velocity for other heights (Voskresenskiy, 2008).

\section{ANALYSIS OF THE RESULTS}

\section{The main parameters of the experimental equipment}

In part of the experiments, some parameters of the experimental equipment have been determined:

- Material (soybean) flow rate,

- Power consumption,

- Air flow velocity.

The results show that the proposed experimental equipment enables to adequately simulate the process of grain storage in containers with active ventilation and conduct experiments with the regulation of basic parameters such as productivity, power consumption, humidity, etc. using modern methods, devices and digital technologies.

The average material flow rate of $Q=$ $66.06 \mathrm{~kg} / \mathrm{h}$ has been obtained. In this case, for 10 working hours a day, the equipment productivity amounts to $Q_{d a y}=660.6 \mathrm{~kg} / \mathrm{day}$. The power consumption per day is at the level of $P_{d a y}=1.178$ $\mathrm{kWh}$. In this case, the specific energy consumption of the process (Kasumov, 2014) is $P_{d a y} / Q_{d a y}$ $=1.78 \mathrm{kWh} / \mathrm{t}$. These findings confirm the results obtained in the calculation by the proposed in (Duisenova et al., 2019) methodology. The difference between the theoretical and experimental results is up to $5 \%$.

\section{Experimental investigation of the ventilation process}

The experiments in ventilation mode (Section 3.3) are performed to determine:

- Change of the material moisture;

- Change of the humidity in the hopper;

- Change of the temperature in the hopper.

Using a Framcomp ${ }^{\circledR}$ Wile 65 grain moisture meter (Fig. 7) the following parameters were measured: 


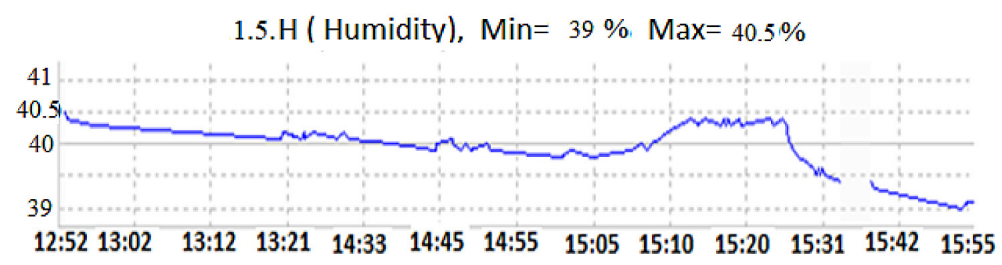

Fig. 9. Humidity change during three-hour ventilating process

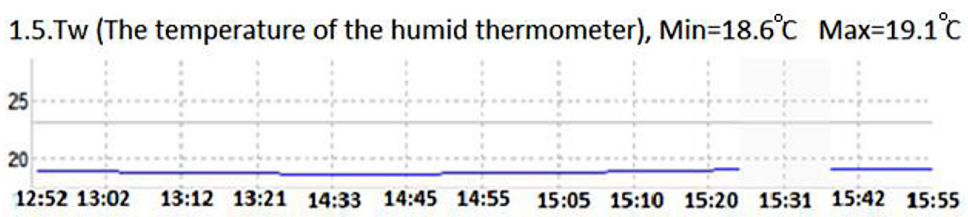

Fig. 10. Temperature change during three-hour ventilating process measured by wet-bulb thermometer

1.3.T (Temperature), $\mathrm{Min}=25.9^{\circ} \mathrm{C}$ Max $=26.9^{\circ} \mathrm{C}$

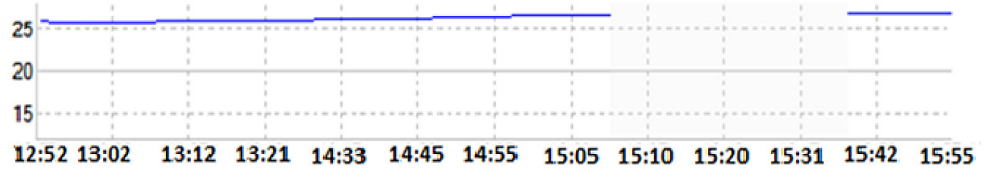

Fig. 11. Temperature change during three-hour ventilating process measured by sensor

- Initial moisture content of grain before ventilation: $15 \%$;

- Residual moisture content of grain after threehour ventilation: $11.8 \%$.

The same results are obtained with the direct (tag) method (GOST 13586.5, 2015).

This indicates a decrease in soybean moisture by $3.2 \%$ over the specified time (three hours). Along with this, continuous control of the humidity and temperature of the air in the container during the experiment was provided using the "Strazh
Klimat" system (Figures 9, 10, and 11). Before ventilation, the moisture content of material was $15 \%$ and the humidity in the container amounted $40.5 \%$. At the end of the ventilation process, these values reached $11.8 \%$ moisture and $39 \%$ humidity, respectively. This correlation is useful for managing the real storage equipment (Fig. 1), where the control panel shows the humidity rate only. Monitoring the temperature and humidity in the container of the experimental equipment enables to study their effect on the drying process, as well as the effect of ventilation on their values.

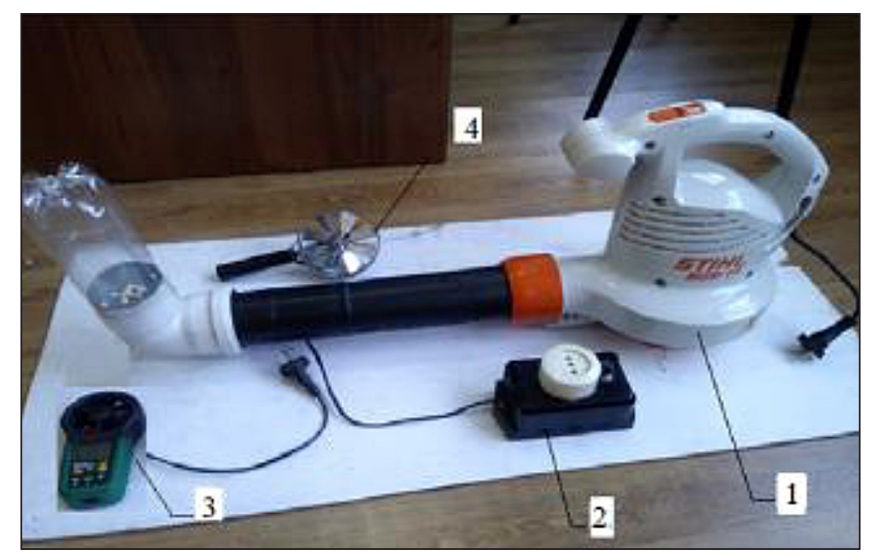

Fig. 12. Experimental equipment for terminal velocity determination (in the laboratory "Agricultural Engineering and Technology" of the Kazakhstan Research Institute of Agriculture Mechanization and Electrification, Almaty, Kazakhstan)

1- blower, 2 - air flow regulator, 3 - windmill digital anemometer, 4 - windmill mechanical anemometer. (Phot. S. Duisenova) 
The results can be used in the mathematical modeling of the drying process (Atykhanov et al. 2015) in real soybean storage equipment.

\section{Air flow velocity}

As mentioned in Paragraph 3.4., at the laboratory "Agricultural Engineering and Technology" of the Kazakhstan Research Institute of Agriculture Mechanization and Electrification, Almaty, Kazakhstan, the soybean terminal velocity has been measured on average $v_{0}=13 \mathrm{~m} / \mathrm{s}$ (with grain moisture content of 15\%). This value differs from the value of $9.41 \mathrm{~m} / \mathrm{s}$ measured in (Polat et al., 2006) for the grain moisture content of $15.3 \%$. The difference can be explained by the difference in soybean varieties.

Using the experimental equipment (Fig. 3), it was found that in order to raise the grain mass to a height of $H=1.5 \mathrm{~m}$, an air flow velocity of $v=20 \mathrm{~m} / \mathrm{s}$ is required. At height of $H=2.0 \mathrm{~m}$, the required air speed is $v=20.1 \mathrm{~m} / \mathrm{s}$. These values can be used as a starting point for calculating the required air velocity for other heights (Voskresenskiy, 2008).

In the laboratory "Agricultural Engineering and Technology" of the Kazakhstan Research Institute of Agriculture Mechanization and Electrification, Almaty, Kazakhstan, experiments have been carried out to establish the necessary air velocity for conveying the grain masses at different heights. This experimental equipment allows for measurements up to a height of 18 meters. The results are shown in Fig. 13. This relationship is of interest and should be tested on the created experimental equipment (Fig. 2) after its development to increase the possible conveying height. In this regard, experiments are planned under real conditions on the existing storage equipment (Fig. 1).

In theoretical calculations, it was found that in order to raise the grain mass to a height of 18 meters, the required estimated air flow velocity should be $26.6 \mathrm{~m} / \mathrm{s}$ (Atykhanov et al., 2019). In practice, the following dependence is usually used to determine the air flow velocity (Martyanova, 2017):

$$
v=2 v_{0}=2 \cdot 13=26 \mathrm{~m} / \mathrm{s}
$$

Experiments have shown that this velocity is sufficient to lift up to 18 meters, but with higher conveyors it must be increased. Moreover, for soybean it is known that the air flow velocity should not exceed $30 \mathrm{~m} / \mathrm{s}$ to prevent damaging the grains (Velocity of an air flow at vertical pneumo transport).

The experimental studies on the created experimental equipment will enable to determine the air velocity in the pneumatic conveyors in question more clearly.

The proposed graph (Fig. 13) can be used to further select the appropriate parameters of the container-modular equipment for storage of soybean with active ventilation.

\section{DISCUSSION}

In the developed experimental model installation, experiments were conducted and the productivity, power consumption, as well as the humidity of soybeans during ventilation, were investigated. Along with this, the humidity and temperature during the experiment were controlled using the "Straj Climate Control" program.

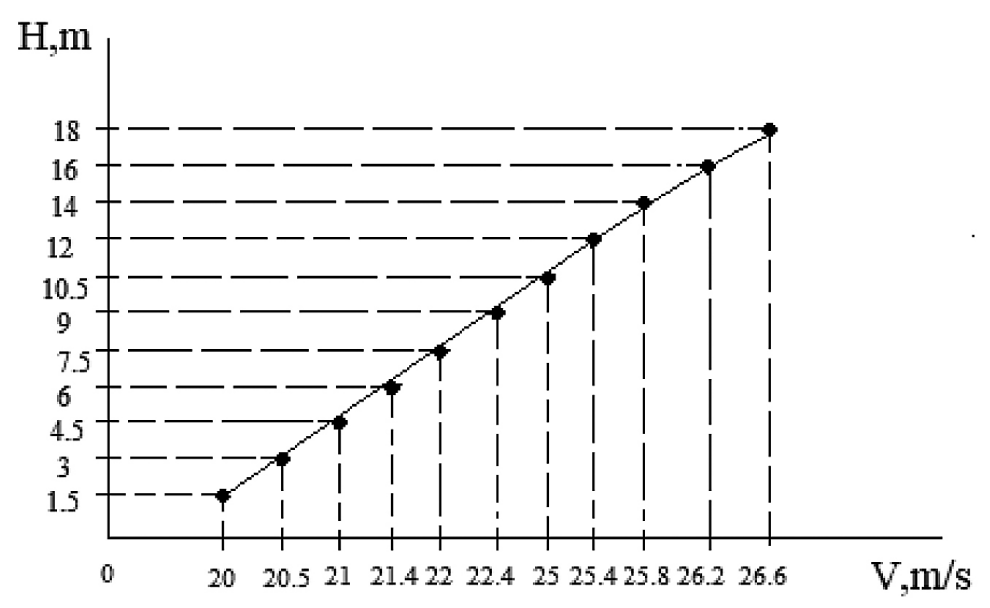

Fig. 13. Relation between conveying height $\mathrm{H}$ and air flow velocity $\mathrm{V}$ 
Moreover, the experimental data were obtained in the laboratory "Agricultural Engineering and Technology" of the Kazakhstan Research Institute of Agriculture Mechanization and Electrification, Almaty, Kazakhstan, on the basis of which it is possible to establish the dependence of the air mass velocity on the height of grain rise (see Fig. 13), i.a. by increasing the height of grain loading increases air flow velocity.

As far as the work of other researchers is concerned, for example, Zhikharev E. A. writes that the air flow velocity of grain in the pneumatic Transporter is 2.0 times greater than the terminal velocity of grain (Zhikharev, 1959). A. P. Kazakov writes that the air flow velocity of the material is $1.25-2.8$ times greater than the terminal velocity of the grain (Kazakov, 1966).

Thus, the analysis of the considered works shows that there are no theoretically justified dependencies between the values of air flow velocity, terminal velocity. In order to select the calculated value of air flow velocity, "the modern theory of pneumatic transport does not provide reliable generalizing formulas" (Kalinushkin et al., 1961). The value of this rate in all studies is established for each type of material experimentally. The resulting graph (Fig. 13) can be used to further select the appropriate parameters of container-modular equipment for soybean storage with active ventilation.

\section{CONCLUSIONS}

In this work, the following provisions were reflected:

1. An experimental equipment that adequately simulates the proposed technology for soybean storage with active ventilation was developed.

2 . With this equipment, the experiments were carried out and the productivity, power consumption of the process, as well as soybean moisture during ventilation were investigated.

3. It was found that the obtained productivity and power data in the theoretical calculation are close in value to the experimental data with a deviation of up to $5 \%$.

4. The theoretical results pertaining to the value of the required air flow velocity for conveying the grain mass to a height of 18 meters were confirmed.

5. The proposed graph (Fig. 13) for selecting the air flow rate for conveying to a certain height is useful to choose the appropriate parameters of the process and the equipment.

\section{Acknowledgements}

The authors express their deep gratitude to colleagues, especially to Professor Omirserik Zhortuylov, from the laboratory "Agricultural Engineering and Technology" of the Kazakhstan Research Institute of Agriculture Mechanization and Electrification, Almaty, Kazakhstan, where some experiments have been carried out.

\section{REFERENCES}

1. Aniskin V.I. 1972. Theory and technology of drying and temporary preservation of grain by active ventilation. Moscow, VIM.

2. Asoiro F.U. and Chidebeluq J.C. 2014. Effect of moisture content on aerodynamic properties of corn seeds (Zea mays). Journal of Agricultural Engineering and Technology, 22(4), 56-65.

3. Atyhanov A.K., Duisenova S.T., \& Karaivanov D.P. 2018. Development of equipment for the storage of soybeans with active ventilation. Mechanization in Agriculture \& Conserving of the Resources, 64(1), 8-10.

4. Atykhanov A., Duisenova S., \& Karaivanov D. 2019. Container-modular equipment for the storage of soybeans with active ventilation for farms of Kazakhstan. Eurasian Journal of Biosciences, 13(2), 1057-1065.

5. Atykhanov A., Karaivanov D., Kassymbayev B., \& Kolev D. 2015. A fruit drying mathematical model. International Journal of Pure and Applied Mathematics, 101(2), 281-288.

6. Atykhanov A.K., Karaivanov D.P., \& Duisenova S.T. 2018. Equipment for storage of grain material with active ventilation. Patent KZ U 3135 A01F 25/00, (24.09.2018).

7. Bokusheva R., Finger R., Fischler M., Berlin R., Marín Y., Pérez F., \& Paiz F. 2012. Factors determining the adoption and impact of a postharvest storage technology. Food Secur., 4, 279-293.

8. Chang C.S., Converse H.H., \& Steele J.L. 1993. Modeling of temperature of grain during storage with aeration. Trans. ASAE. -St.Joseph(Mich.), 36(2), 509-519.

9. Chi Y.H., Ahn J.-E., Yun D.-J., Lee S.Y., Liu T.-X., \& Zhu-Salzman K. 2011. Changes in oxygen and carbon dioxide environment alter gene expression of cowpea bruchids. J. Insect Physiol., 57, 220-230.

10. Duisenova S., Atykhanov A., \& Karaivanov D. 2019. Justification of the parameters of a pneumatic conveyor for active ventilation of soybean 
during storage. MATEC Web of Conferences, 287 (6th International BAPT Conference "Power Transmissions 2019”). DOI: https://doi.org/10.1051/ matecconf/201928704004.

11. Fleurat-Lessard F. 2017. Integrated management of the risks of stored grain spoilage by seedborne fungi and contamination by storage mould mycotoxins - An update. J. Stored Prod. Res., 71, 22-40.

12. GOST 13586.5. 2015. Grain. Method for determination of moisture content.

13. Jangurazov B.O. and Jangurazov K.B. 2013. Save the Golden grain of Kazakhstan. Almaty: Aleyron.

14. Kalinushkin M.P., Orlovsky Z.E., \& Segal I.S. 1961. Pneumatic transport in construction. Moscow: Stroizdat.

15. Kamanula J., Sileshi G.W., Belmain S.R., Sola P., Mvumi B.M., Nyirenda G.K.C., Nyirenda S.P., \& Stevenson P.C. 2010. Farmers' insect pest management practices and pesticidal plant use in the protection of stored maize and beans in Southern Africa. Int. J. Pest Manag., 57, 41-49.

16. Kasumov N. 2014. The determination of the average values of energy intensity labor of different categories of workers depending on the physical activity, Machinery and equipment for the village, 5, 27-29.

17. Kazakov A.P. 1966. Pneumatic transport. Device, theory and calculation. Gorky: Volgo-Vyatka book publishing house.

18. Kazanina M.A. 1988. Processing and storage of agricultural production. Minsk: Uradzhay.

19. Lamond W.J. and Graham R. 1993. The relationship between the equilibrium moisture content of grass mixtures and the temperature and humidity of the air. Journal of Agricultural Engineering Research, 52(4), 327-335.

20. Loveykin V.S., \& Kostin A. 2012. Multimass model of the motion of the scraper conveyor considering dissipative forces. Scientific Papers (branch of engineering, construction). PoltNTU, 1(31), 35-43.

21. MAK - Ministry of Agriculture of the Kazakhstan. 2015. On approval of the rules for storage of grain. Order of the Minister of Agriculture of the Republic of Kazakhstan dated June 26, 2015, No. 11839.
22. Martyanova A.Y. 2017. Improving the methods for calculating vacuum deducting systems in cement and dry building mixtures plants. Ph.D. thesis, Saint-Petersburg State University of Architecture and Civil Engineering, Russian Federation.

23. Monitoring system Alarm-Climate. http://softron. com.ua/

24. Navarro S. 2006. Modified atmospheres for the control of stored-product insects and mites. In Insect Management for Food Storage and Processing; Elsevier: Amsterdam, The Netherlands. 105-146.

25. Parimala K., Subramanian S., Mahalinga Kannan S., \& Vijayalakshmi K. 2013. Seed storage techniques - a primer. CIKS, Chennai, India.

26. Polat R., Atay U., \& Saglam C. 2006. Some Physical and Aerodynamic Properties of Soybean. Journal of Agronomy, 5(1), 74-78.

27. Sakun V.A. 1974. Drying and active ventilation of grain and green feed. Moscow, Kolos.

28. Silva J.B., Carrão-Panizzi M.C., \& Prudencio S.H. 2009. Chemical and physical composition of graintype and food-type soybean for food processing. Pesqui Agropecu Bras., 44(11), 777-784.

29. Singh G. 2010. The Soybean: Botany, production and uses. CABI, Wallingford, UK.

30. Turaev N.S, Brus I.D., \& Kantaev A.S. 2015. Calculation of pneumatic conveying installations. Tomsk, Polytechnic University of Tomsk Publisher.

31. Vasilev A.N. 1986. Statistical characteristics of atmospheric parameters for active seed ventilation. Automation and computers in agricultural production. Proceedings of V.P. Grachenkin MIISP, 77-82.

32 . Velocity of an air flow at vertical pneumo transport. https://chem21.info/info/1606838/

33. Voskresenskiy V.E. 2008. Pneumatic conveying, dust collection, and ventilation systems at woodworking plants. Theory and practice. Politekhnika, Saint-Petersburg.

34. Yukish A.E. and Ilina O.A. 2009. Machinery and technology of grain storage. DeLi, Moscow.

35. Zhikharev E.A 1959. Experimental study of the nature of particle motion in pneumatic transport pipelines. Engineering physics journal, 2(2), 25-31. 